\title{
GENERALUL GHEORGHE BĂGULESCU, PERSONALITATE MARCANTĂ A SECOLULUI XX
}

\author{
Prof. dr. Ilie Popa,
}

Universitatea din Pitești, Departamentul de Electronică, Calculatoare și Inginerie

Electrică, Pitești, Argeș, 110040, Romania

Fundația Culturală Memoria - filiala Argeș, Pitești, 110128, Romania

ci.popa@yahoo.com

\begin{abstract}
The paper presents the life and activity of a remarkable personality in the history and culture of Romania during the first half of the $20^{\text {th }}$ century, less known in Romania, General Gheorghe Băgulescu. Originally from the Argeş area, Gheorghe Băgulescu had all the military grades, participated as officer in the Second Balkan War and in the First World War, receiving several orders and medals, was involved in the act of the Great Romanian Union, had a rich diplomatic mission activity in the Far East, in Japan, China and Manchuko, as a military and airnavy attaché of the Romanian Legation, had a remarkable cultural activity. Being a profound and subtle connoisseur of Japanese tradition and spirituality, in 1936 he writes and publishes a novel in three volumes titled "Yamato Damashii", in which he masterly presents the era of honor, dignity and the flourishing of the Japanese spirit during the Feudal Japan. For this novel, he receives the Nipone Academy Award for ,the best novel about Japan written by a foreigner" and he is the only foreigner received by Japan's Gishi-Kai National Academy. Due to his vehemently expressed anti-fascist beliefs, the Nazi authorities staged a failed attempt and finally settled in France, in Nice where he received political asylum. He also publishes other books and numerous articles. In France he receives the „Grand Prix de Littérature” for the „Yamato Damashii” trilogy and is elected member of the Académie des Lettres et des Arts in Paris. During his stay in the Far East, he gathers an impressive collection of Japanese art exhibited in a museum in Nice, France and a small part at the National Art Museum in Bucharest. He died and was buried in Nice in 1963, but expressed his will to be brought to his ancestors properties of in Ştefăneşti, near Piteşti, Arges county after his death, which has not been accomplished until now.

În anul 2018, anul centenarului Marii Unirii a românilor, se cuvine să amintim marile personalități ale timpului care au avut un rol semnificativ în acest act de importanță crucială. O astfel de personalitate este și generalul Gheorghe Băgulescu pe care îl evocăm în cele ce urmează.
\end{abstract}

\section{Origine, școală}

Generalul Gheorghe Băgulescu, Figura 1 [1], este o personalitate remarcabilă mai puțin cunoscută din istoria României secolului al XX-lea. Aducerea lui în conștiința publică se datorează îndeosebi scriitorului şi diplomatului argeșean Mihai Epure care 1-a descoperit în perioada cercetărilor sale în arhiva Ambasadei Romane din Tokio, unde se afla în misiune diplomatică. Era mult mai bine cunoscut în mediile diplomatice ale
Japoniei şi în mediile culturale de acolo, fiind, la vremea lui, singurul străin primit în rândurile Academiei Naţionale Japoneze, decât in Romania. Mihai Epure a fost impresionat atât de mult de personalitatea sa fabuloasă încât i-a dedicat sute, poate mii de ore de studiu și a scris două cărți memorabile: Aproape de Soare Răsare [2], Editura Cartega, 2002; Dor de Sakura [3], Editura Cartega, 2006.

Data și locul nașterii lui Gheorghe 
Băgulescu sunt prezentate diferit: 11 noiembrie 1890 în Ștefănești, județul Argeș [1]; 1 noiembrie 1890 în Flămânda, România [4]; 11 noiembrie 1890 în plasa Iancu, județul Brăila [5]. Din documentele de la arhivele din Pitești rezultă că părinții şi bunicii lui Băgulescu își au originea la Ştefănești Argeș, situat la circa $4 \mathrm{~km}$ de orașul Pitești, unde au posedat 20 ha de viță de vie și două case. Aici tatăl său, Petre, fusese învățător și preot, dar împreună cu soția și ceilalți doi băieți locuiau la Flămânda, județul Brăila.

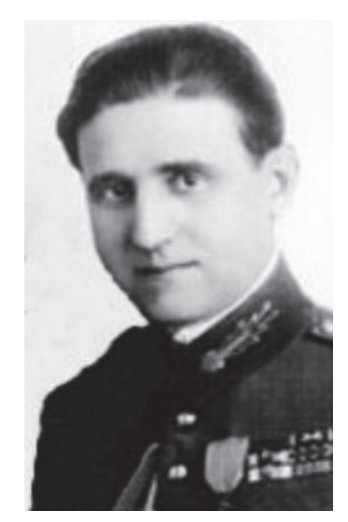

Figura 1. Generalul Gheorghe Băgulescu.

Asemenea celorlalți doi frați ai săi, Gheorghe Băgulescu a absolvit ca șef de promoție liceul Nicolae Bălcescu din Brăila în anul 1907 și urmează Școala Militară de Ofiţeri de Infanterie, fiind avansat în anul 1912, la gradul de sublocotenent. A urmat Școala militară de ofițeri de infanterie, apoi un stagiu la Școala regională de schi și alpinism din Briancon-Grenoble, cursul de informații Alpins, Franța și Şcoala Superioară de Război.

\section{Activitatea militară, diplomatică și culturală}

La 20 iunie 1913 este mobilizat la Regimentul I Vânători, participând cu acesta la campania din Bulgaria în al Doilea Război Balcanic și, după cei doi ani de neutralitate ai României când, conform hotărârii Consiliului de coroană, țara intra în Primul Război Mondial alături de Franța, Anglia, Rusia și Italia, la 16 august 1916, căpitanul Gheorghe Băgulescu este mobilizat în Regimentul 66
Infanterie, desfășurând acțiuni de luptă pentru apărarea Bucureștiului. În aceste lupte a fost rănit și apoi spitalizat. A revenit în rândurile armatei române și a participat la cunoscutele bătălii de la Oituz, Mărăști, Mărășești, Nămoloasa, Galați, în urma cărora faptele sale de arme au fost răsplătite cu Ordinul Mihai Viteazul, clasa a III-a (Decret nr. 131 din 25.01.1918:, , Pentru vitejia și avântul cu care a comandat compania in luptele din valea Putnei și de la Oituz. In ziua de 29 iulie 1917 a atacat cu energie și a cucerit cota 408, sat Grozești pe care a menținut-o în fața contraatacurilor inamice. La 3 august a atacat viguros un detașament inamic ce amenința întreaga poziție.") [2, 3, 6], Ordinul Steaua României cu spade, Ordinul Coroana României, Ordinul Sf. Vladimir, clasa a IV-a cu spade, Medalia „Avântul Țării” și Legiunea de onoare in grad de cavaler.[4, 7, 8]

În a doua parte a campaniei din 19181919, este mutat la Regimentul 1 Vânători, unitate în cadrul căreia se remarcă în luptele purtate de armata română în Transilvania.

Înzestrat cu un real talent scriitoricesc, publică numeroase articole de ziar și revistă, precum şi volume de proză inspirate din realitățile crude ale războiului.

Încheierea Păcii de la București cu Puterile Centrale, din data de 7 mai 1918 îl surprinde pe căpitanul Gheorghe Băgulescu la Târgu-Neamț, în Corpul Vânătorilor de Munte și scârbit de condițiile umilitoare și dezastruoase ale păcii, la data de 26 mai 1918 va tipări și publica (lipi pe ziduri) la TârguNeamț și Iași un manifest extrem de violent la adresa guvernului Alexandru Marghiloman și a "presei mercenare, puse în slujba inamicului". a lipit pe zidurile Iașilor un manifest violent la adresa lui Marghiloman şi a "presei mercenare, puse în slujba inamicului", în care îl ameninţa pe Marghiloman că "trebuie să existe pe undeva un suflet curat, un revolver încărcat sau o grenadă".[6] A fost dat însă achitat şi a existat o puternică reacţie populară în sprijinul său, fiind de altfel sprijinit de cavalerii ordinului Mihai Viteazul.

Manifestul a fost considerat un act de ultraj la adresa guvernului și căpitanul Gheorghe Băgulescu este trimis în judecată, la 
Tribunalul Militar al Corpului IV Armată. La data de 5 septembrie 1918 completul de judecată respinge acuzația de ultraj și îl achită pe inculpat, dar este pedepsit pe linie disciplinară fiind mutat din Corpul Vânătorilor de Munte în cadrul Regimentului 14 Dorobanţi, , Roman”, unde va executa 60 de zile de arest.[6]

După căderea guvernului condus de Alexandru Marghiloman, în noul guvern este numit ministru de război, generalul Eremia Grigorescu, sub a cărei comandă luptase Gheorghe Băgulescu în Primul Război Mondial și, apreciindu-l în mod deosebit, ministrul îl selectează pe căpitanul Băgulescu în delegația militară care a aduce actul Marii Uniri de la Alba Iulia la București pe traseul: Alba Iulia - Sibiu Țara Loviștei - Curtea de Argeș București. [1, 9, 10]

După încheierea Războiului pentru Întregirea României va continua seria de articole și nuvele în care proslăvește eroismul ostașilor români și condamnă profitorii și demagogii.

Încă din tinerețe, Gheorghe Băgulescu vorbea bine limbile franceză, germană și italiană. Devine membru al Societății Scriitorilor Romani în anul1921.

În anul 1924, având gradul de maior, a fost arestat şi dat în judecată pentru simpatii legionare, fiind închis la închisoarea Jilava unde îşi petrece Paştele acelui an. În Figura 2 se prezintă articolul apărut în cotidianul Clujul [12]. Gheorghe Băgulescu s-a căsătorit la data de 31 ianuarie 1926 cu Elena Dimitriu, căsătoria fiind celebrată la biserica Sf. Spiridon în baza aprobării Corpului vânătorilor de munte iar naşul de cununie a fost Octavian Goga, poet și viitor prim-ministru.

La 7 decembrie 1926 în București s-a născut o fetiță, Elena Georgiana, naș de botez fiind tot poetul Octavian Goga.

În urma analizei arhivelor militare ale UM 02405 Pitești și studiului foilor matricole ale ofițerului Gheorghe Băgulescu se remarcă faptele sale de arme care, prin natura misiunilor încredințate, se afla în preajma lui Carol al IIlea, a mareșalului Ion Antonescu, a împăratului Japoniei, precum și a unor distinşi diplomaţi ale căror nume au rămas în istorie.

În această perioadă are o bogată activitate publicistică. Pe lângă numeroasele articole publicare în ziare și reviste, a publicat și următoarele cărți: "Rânduri de la Frontieră" - Locotenent G. Băgulescu, Tipografia Georgescu, Craiova Str. Ştirbei-Voda nr.35; "Zile de Energie. Impresii și povestiri de pe front 1916-1917”' (Ed.II-a. Căpitanul G. Băgulescu Regimentul Vânători de munte) Institutul de arte grafice C. Sfetea. București - 1919; "Zile Triste", cu prefață de autor, căpitan G. Băgulescu și cu o scrisoare de Nicolae Iorga, Editura Tipografiei "Lupta", N. Stroilă, Calea Victoriei 113, 1919; "Antiquitas rediviva" (roman istoric), Craiova, 1926.[4]

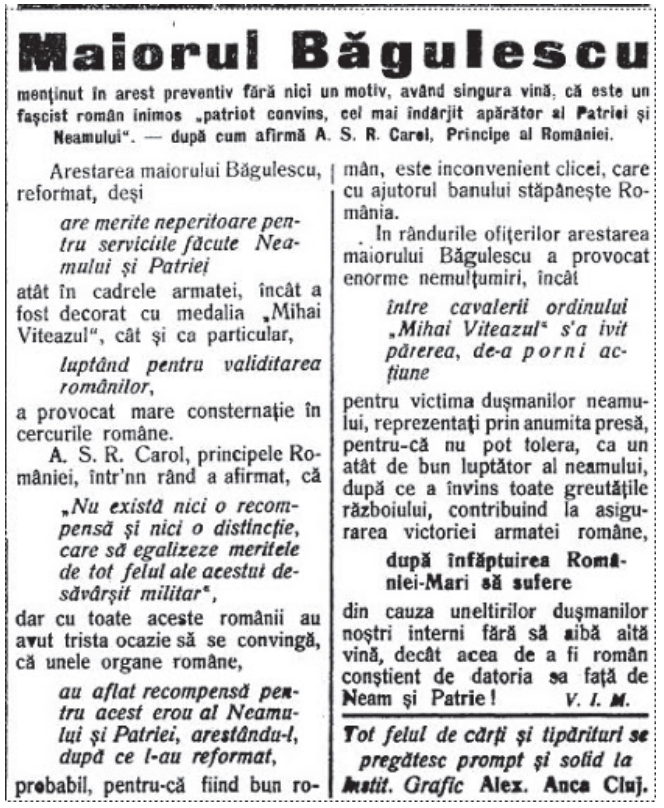

Figura 2. Articol din ziarul Clujul, din 27 aprilie 1924.

În perioada 1935 - 1939 a fost ataşat militar şi aero-naval al Legaţiei României de la Tokio, Japonia, în China şi Manchuko [4, 6, 16]. Aici îşi însuşeşte repede şi bine limba japoneză, desfăşoară o largă şi bogată activitate de propagandă românească pe teritoriul nipon, dar, în acelaşi timp, studiază temeinic istoria şi obiceiurile japonezilor procurând numeroase obiecte de artă, o mică parte dintre ele, donându-le ulterior Muzeului Naţional de Artă din Bucureşti.

Conform celor afirmate chiar de generalul Băgulescu, scopul colecţiei de artă era legat 
de: "Gândul ca și românii mei, care nu au putut vizita China şi Japonia, să-şi facă o idee mai justă asupra manifestaţiilor sufletești, culturale şi artistice ale acestor doua naţiuni, cu civilizaţie multimilenară..." A strâns piesele colecţiei şi cu gândul "de a pune la îndemâna tineretului nostru studios, un material artistic, prin înființarea unui muzeu de artă chino-japonezăa, muzeu pe care $\hat{\imath} l$ voi dărui ţării, fără nici o pretenție”. [1] Dar a pus o singură condiţie. Aceea de a dona statului toate lucrările sale numai dacă se construiește, în timp de doi ani, o clădire în formă de pagodă în Herastrău, care să adăpostească și să fie expusă întreaga sa colecție. Trebuie menționat că fusese expusă colecția sa la București, Ateneul Român 1938 şi 1940. Din păcate, clădirea nu a fost construită, iar Băgulescu, supărat, a contramandat donaţia şi a luat lucrările cu el în noul periplu în Japonia şi mai deoparte. Colecţia strânsă de ataşatul nostru militar în
Japonia cu piese vechi de sute si mii de ani străbătuse peste $12.000 \mathrm{~km}$ şi venise în ţară în 3 vagoane de tren. Numărul pieselor era de 2.773, dintre care: 720 tablouri; 12 paravane mari; 18 paravane mici; 2.017 gravuri, vase, monede, brocarturi, sculpturi în bronz, piatră, marmură, fildeş, lemn preţios.

Fin şi profund cunoscător al civilizaţiei japoneze fiindu-i un mare admirator, scrie şi publică în 1936 un roman în trei volume intitulat "Suflet japonez" în care prezintă în mod magistral epoca de onoare, demnitate şi înflorire a spiritului nipon din timpul Japoniei feudale. În limba română, cartea a apărut mai întâi în facsimil la editura ziarului "Universul", apoi în volum la aceeași editură în 1939, pentru ca mult mai târziu să fie reeditat în volum la editura Cartega în colaborare cu editura Nipponica, în 2004, Figura 3.

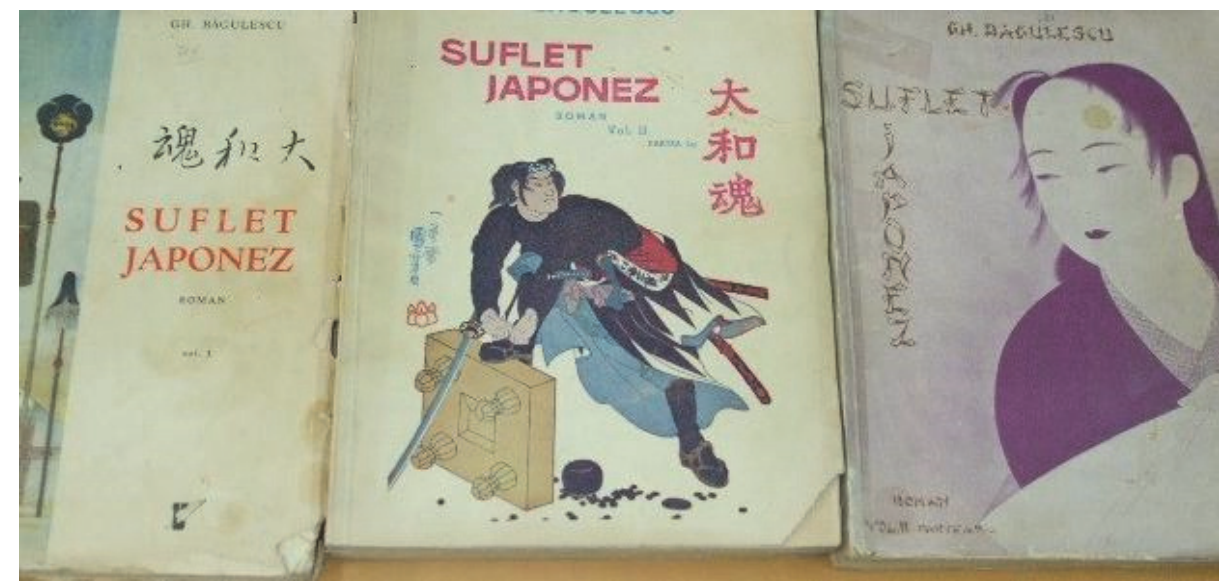

Figura 3. Coperta romanului în limba română [13].

Romanul a avut primul volum tradus și publicat în limbile engleză și franceză sub titlul "Yamato Damashii: A Romance" de Kenkyusha Printing Company în 1938 și în limba japoneză sub titlul "Yamato Damashii"de aceeași editură, Kenkyusha Printing Company în 1943. Trilogia bazată pe legenda celor patruzeci și șapte de samurai din clanul Ako ce devin ronini, a provocat reacţii impresionante în Japonia și primeşte premiul Academiei de Ştiinţe Nipone pentru ,cel mai bun roman despre japonezi scris de un străin", până la momentul apariţiei ei. Tot ca urmare a publicării acestei cărţi, a fost, la vremea aceea, singurul străin primit în rândurile Academiei Naţionale Gishi-Kai a Japoniei şi, pentru "servicii eminente aduse în relaţiile bilaterale", Împăratul Japoniei, Hirohito, i-a decernat în anul 1939 înaltul ordin "Tezaurul Sacru", clasa a III-a. Este de amintit faptul că scriitorul și diplomatul Mihai Epure a spus că minunatul roman, "Şogunul"de James Clavel s-ar fi inspirat mult din atmosfera cărţii "Suflet japonez" a lui Gheorghe 
Băgulescu.[14] El însuşi este puternic îndrăgostit de Japonia, ducând o viaţă dublă, cu o soţie legitimă şi o fetiţă în Romania şi cu o altă soție nelegitimă şi un băieţel în a doua sa patrie, Japonia, Figura 5 [15].

În 1939 şi-a dat demisia din armată, în semn de protest faţă de instituirea dictaturii personale a regelui Carol al II-lea, dar când regele a abdicat, a fost reprimit în armată, fiind avansat la gradul de general.

În 1940 a fost ales preşedinte al Asociaţiei cavalerilor Ordinului Mihai Viteazul.

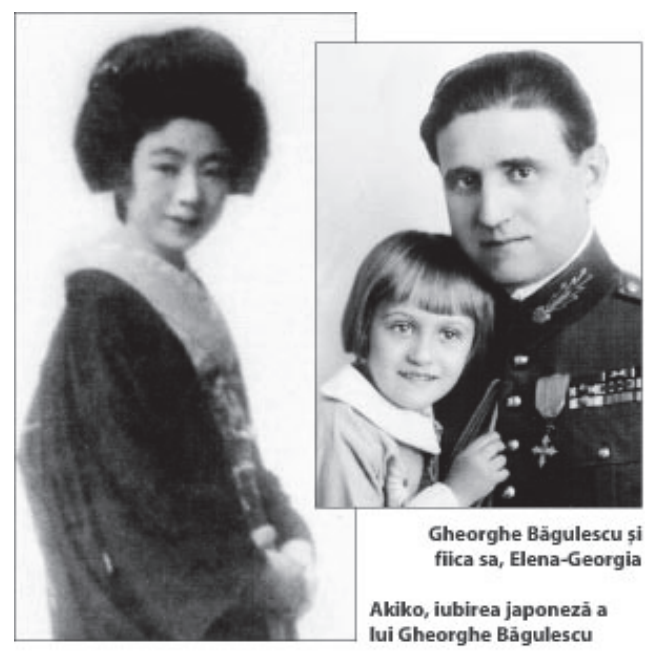

Figura 5.

A avut câteva conflicte şi cu Mareşalul Antonescu (Băgulescu și Antonescu fuseseră colegi și la școală, șeful de promoție fiind generalul) care, în 1941, îi oferă Ministerul Internelor în guvernul său, dar Băgulescu nu acceptă. Se spunea chiar că Băgulescu a fost contactat înaintea lui Antonescu pentru a prelua șefia statului, după abdicarea regelui în 1940. Revine în ţară și, în anul 1941, Băgulescu este retrimis ca ministru extraordinar şi plenipotenţiar în Japonia, până în 1943, când își manifestă dezacordul faţă de război şi de regimurile totalitare, intrând în conflict cu autorităţile japoneze.

\section{Arestarea, exilul și testamentul}

Aflat la mii de kilometri de Europa, în misiunea diplomatică a unei ţări aliate într-o ţară ce întregea Axa Roma-Berlin-Tokio, generalul Băgulescu își exprimă tranşant ideile sale antinaziste, fapt ce atrage după sine arestarea sa la domiciliu mai întâi în Japonia și apoi în China, cu interdicţia de a mai lua legătura acolo cu lumea diplomatică, mișcările fiindu-i strict supravegheate.

Publicarea unor articole în 1942, apărute mai întâi în presa japoneză, sub forma unei lucrări pacifiste intitulată "Noua religie", în care pacea era noua religie, evident "antinaziste, antitotalitare", moment în care jocurile politice la nivel mondial încă nu erau făcute, precum și mesajul său către țară interceptat de germani, prin care avertiza despre intenția lui Hitler și Stalin de a împărți Europa, scindând România în două, în 1943, la ordinul lui Hitler, Gestapo-ul organizează un atentat la viaţa lui Băgulescu, comis chiar de unul dintre angajaţii Legaţiei. Atentatul eșuează, generalul Băgulescu scapă cu viaţă, fuge în Statele Unite cu ajutorul unor diplomaţi elveţieni și apoi se stabileşte în Franţa, la Nisa.[1]

După capitularea Japoniei, romanul "Suflet japonez" a fost interzis şi în Japonia de către americani, iar după venirea la putere a regimului comunist în România, generalul Băgulescu a fost etichetat drept transfug și criminal de război, familia căzând în mizerie și uitare. Colecția sa de artă, impresionantă prin valoare și cantitate, a cunoscut un periplu sinuos, reflectând întocmai destinul colecționarului.

Îşi continuă activitatea literară în Franța, publicând în 1947 cartea sa "Noua religie" în două volume, Ediția Vitiano. De asemenea, în 1950 la Paris mai publică "Race de vipères; la vérité devant Dieu et devant les hommes", Éditions M.B. Pentru meritele sale pe tărâm literar, primește marele premiu "Grand Prix de Littérature" pentru trilogia "Yamato Damashii" și este ales membru al Academiei de Litere și Arte (Académie des Lettres et des Arts) din Paris. Generalul De Gaulle îi oferă azil politic iar în 1950 îl cunoaşte pe primarul localităţii Menton, unde va dona 683 stampe şi 56 de chimonouri. Stabilit la Nisa, el deschide în acest oraş un muzeu de artă japoneză pentru care a fost decorat cu Ordinul japonez "Tezaurul sacru", clasa a III-a, de către împăratul Japoniei şi primește titlul de "cetăţean de onoare al oraşului Nisa".[1] 
În 1973 Ministerul Culturii a achiziţionat o parte din colecţia generalului Băgulescu şi astfel, o mare parte a colecţiei de stampe japoneze şi orientale ale Muzeului Naţional de Artă din Bucureşti este constituită din donaţiile făcute de acesta.

Pentru o perioadă, înainte să moară, a fost prim ministru al românilor din exil, după generalul Rădescu.

Generalul Gheorghe Băgulescu a decedat la data de 26 noiembrie 1963, dar diferitele surse de informare nu s-au pus de acord privind locul morţii acestuia: Nisa sau Menton, ambele localităţi fiind în aceeaşi provincie franceză. Demn de remarcat este faptul că Primăria din Nisa i-a ridicat argeșeanului o statuie pe postamentul căreia a fost scris: "Gheorghe Băgulescu - un diplomat, un erou".[5]

Ultima sa dorință lăsată și în testament nu s-a îndeplinit încă. "Când timpul va permite, rog să fiu transportat la proprietatea mea de la Florica, dar numai într-o Românie liberă". Iată conținutul testamentului: „Doresc să fiu inmormântat în plină lumină, pentru a fi aproape de soare. În uniformă, nu pentru spiritul militar, ci pentru că în aceste haine sunt impregnate amintiri din țara mea și din activitatea mea de a o apăra demn contra oricărei aserviri. Când timpul va permite rog să fiu transportat la proprietatea mea de la Florica, dar numai într-o Românie liberă. $O$ stelă să fie ridicată lângă mormântul meu în memoria celor morți în exil, departe de patria lor, de familiile lor, în memoria celor rămași in țară, sunt morți în închisori, în lagăre sau nedreptățiți. Am suferit mult în această lume pentru adevăr și de aceea nu regret. Mai periculos decât bomba atomică pentru mine este demagogia care duce la anarhie, la dezechilibrul spiritului sau la dictatură".[5]

Este trist că trupul lui Gheorghe Băgulescu se află încă într-un cimitir din Franţa deşi prin testament a cerut să fie înmormântat la proprietatea sa de la Florica, astăzi orașul Ștefănești de lângă Pitești, reședința județului Argeș.

Iată ce spune scriitorul și diplomatul Mihai Epure în legătură cu fabuloasa colecție strânsă cu trudă și migală de ilustrul nostru înaintaş, una dintre cele mai reprezentative personalități românești ale primei jumătăți a secolului al XX-lea: "Este cazul ca autoritățile române împreună cu urmaşii generalului-diplomat să facă demersurile necesare pentru a recupera acele comori și a le aduce în țara. Recuperarea și introducerea lor în circuitul național, ca și reeditarea trilogiei sale "Suflet japonez", ar dovedi indubitabil generației tinere dimensiunea reală și perenă a unuia dintre cei mai străluciți soli ai României în îndepărtata Japonie." [15]

\section{Bibliografie}

[1] Revista Agressive, Lavinia Năstase, "Dorința testamentară a celui mai bogat general argeșean nu a fost îndeplinită, incă!’”, 27 Februarie 2016, http://www.revistaagressive.ro/personalit ati/22-dorinta-testamentara-a-celui-maibogat-general-argesean-nu-a-fostindeplinita-inca.html

[2] Mihai Epure, "Aproape de Soare Răsare", Editura Cartega, 2002.

[3] Mihai Epure, "Dor de Sakura", Editura Cartega, 2006.

[4] wikipedia.org/wiki/Gheorghe_Băgulescu

[5] M.I., "Generalul Gheorghe Băgulescu, un diplomat argeşean la Tokio", cu contribuția col. (r) Gheorghe Rădescu, Jurnalul de argeș, Joi, 14 Februarie 2013, http://www.jurnaluldearges.ro/index.php/ component/k2/item/5747-generalulgheorghe-bagulescu-un-diplomatargesean-la-tokio

[6] Sorin Grumus,, Generalul Gheorghe Băgulescu, colecționar de artă, diplomat și scriitor militar, revista Melidonium, 26 februarie 2017 , https://www.melidonium.ro/2017/02/26/g eneralul-gheorghe-bagulescu-colectionarde-arta-diplomat-si-scriitor-militar/

[7] Stănescu Eugen, Preda Gavriil, Cosma Mircea, Stănescu Iulia, "Cavaleri ai ordinului militar de război, , Mihai 
Viteazul", Editura SALGO, Sibiu, 2012.

[8] Revista, , Viaţa Militară” nr. 1-4/2011.

[9] Buzatu, Gheorghe, Cheptea, Stela, Cîrstea, Marusia, editori - "Pace şi război (1940-1944) Jurnalul Mareşalului Ion Antonescu”, volumul I, Casa Editorială Demiurg, Iaşi, 2008.

[10] Călugăru, Geo - "Generalul Gheorghe Băgulescu In memoriam - 40 ani de la trecerea sa în nefiinţă, articol.

[11] "Generals from Romania". Generals.dk. Retrieved 2008-11-24.

[12] Clujul, ziar independent, articol, 27 aprilie 1924

[13] https://www.okazii.ro/suflet-japonez- vol-1-vol-2-partea-1-2-an-1939

[14] Mihaela Hașu Bălan, Radiografii culturale: Exponenți ai relațiilor româno-nipone din veacul trecut, Revista Astra 1-2, 2015 https://www.revistaastra.ro/literatura/

[15] Stan Constantin, Un adevărat român, Ziarului Financiar din data de 22.09.2006.

[16] Adrian Bunea, Diplomați români în perioada interbelică. General de divizie Gheorghe Băgulescu, București 2011 http://kenshinaikidodojo.blogspot.ro/201 3/10/generalul-gheorghe-bagulescufin.html

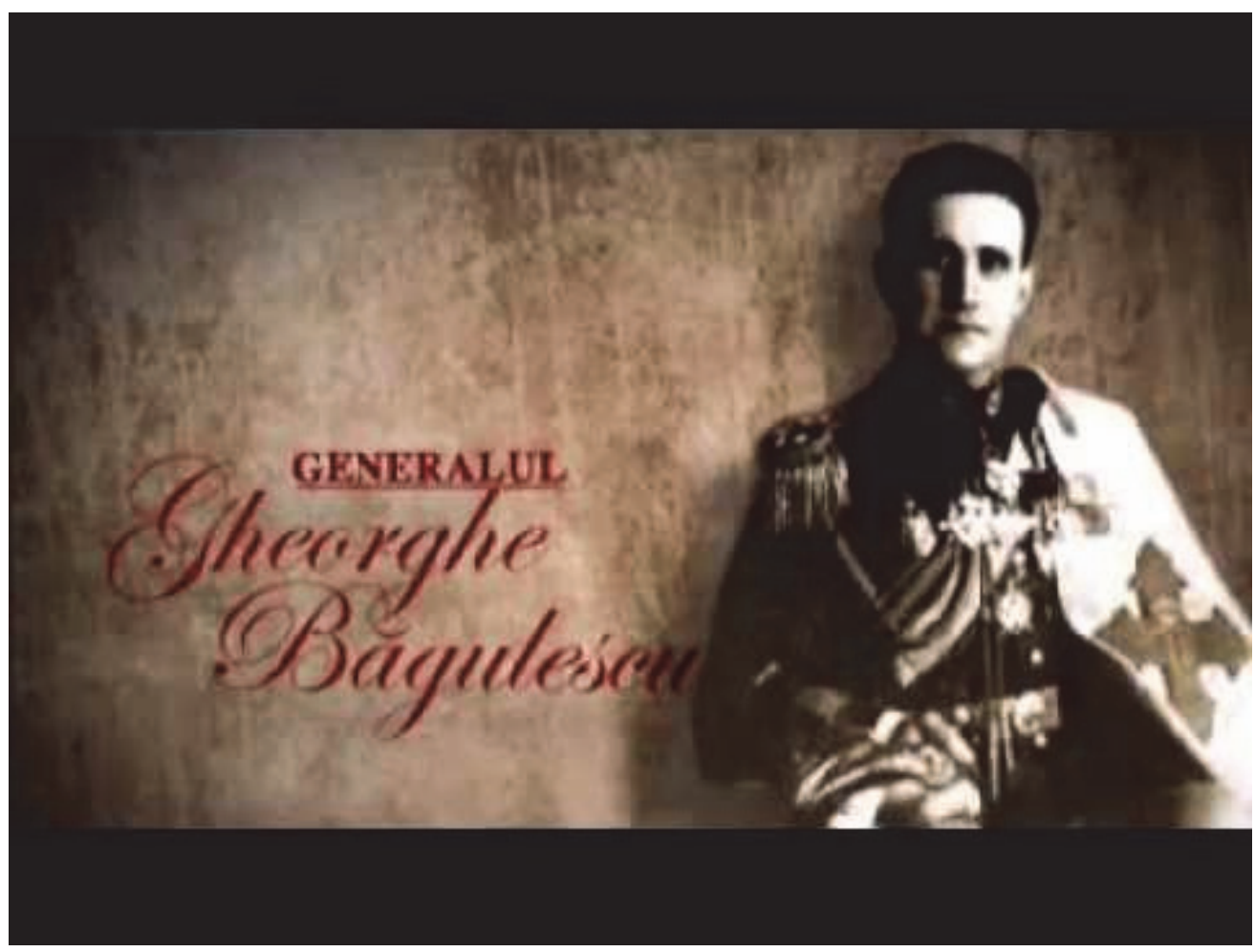

